\title{
Projected changes to wind loads coinciding with rainfall for building design in Canada based on an ensemble of Canadian regional climate model simulations
}

\author{
Dae II Jeong ${ }^{1}$ (D) Alex J. Cannon ${ }^{2} \cdot$ Robert J. Morris ${ }^{3}$
}

Received: 19 November 2019 / Accepted: 14 May 2020/Published online: 21 May 2020

(C) The Author(s) 2020

\begin{abstract}
Strong wind coinciding with rainfall is an important weather phenomenon in many science and engineering fields. This study investigates changes in hourly extreme driving rain wind pressure (DRWP) — a climatic variable used in building design in Canada - for future periods of specified global mean temperature change using an ensemble of a Canadian regional climate model (CanRCM4) driven by the Canadian Earth system model (CanESM2) under the Representative Concentration Pathway 8.5 scenario. Evaluation of the model shows that the CanRCM4 ensemble reproduces hourly extreme wind speeds and rainfall $(>1.8 \mathrm{~mm} / \mathrm{h})$ occurrence frequency and the associated design (5-year return level) DRWP across Canada well when compared with 130 meteorological stations. Significant increases in future design DRWP are projected over western, eastern, and northern Canada, with the areal extent and relative magnitude of the increases scaling approximately linearly with the amount of global warming. Increases in future rainfall occurrence frequency are driven by the combined effect of increases in precipitation amount and changes in precipitation type from solid to liquid due to increases in air temperature; these are identified as the main factors leading to increases in future design DRWP. Future risk ratios of the design DRWP are highly dependent on those of the rainfall occurrence, which shows large increases over the three regions, while they are partly affected by the increases in future extreme wind speeds over western and northeastern Canada. Increases in DRWP can be an emerging risk for existing buildings, particularly in western, eastern, and northern Canada, and a consideration for managing and designing buildings across Canada.
\end{abstract}

Keywords Climate change $\cdot$ Design buildings $\cdot$ Driving-rain wind pressure $\cdot$ Rainfall $\cdot$ Wind speed

Dae Il Jeong

daeil.jeong@ canada.ca

Extended author information available on the last page of the article 


\section{Introduction}

Simultaneous occurrence of wind and rain is an important weather phenomenon in a number of areas, including atmospheric science (Hovind 1965; Johansson and Chen 2003), catchment hydrology (Blocken et al. 2005), agriculture and forestry (Van Stan et al. 2011), soil erosion (Foulds and Warburton 2007), energy infrastructure (Kikuchi et al. 2003), and buildings (Blocken and Carmeliet 2004; Mirrahimi et al. 2015). Strong winds coinciding with rainfall, in particular, have been considered in the design and construction of buildings because wind pressures combined with rainwater can result in severe damage via inflow of water through joints or cracks in the building envelope (National Research Council Canada (NRCC), 2015). Hence, driving-rain wind pressure (DRWP), defined as hourly wind pressure with rainfall exceeding a certain threshold (i.e., $1.8 \mathrm{~mm} / \mathrm{h}$ ), is an important wind load that is incorporated into design standards of buildings in Canada (e.g., NRCC 2015; Canadian Standard Association (CSA) 2018).

Increases in mean and extreme wind speeds have been projected for western, eastern, or northern parts of Canada by the end of this century in multi-model global climate model ensembles from CMIP3 (Coupled Model Intercomparison Project Phase 3) and CMIP5 (Mclnnes et al. 2011; Intergovernmental Panel on Climate Change (IPCC) 2012; Kumar et al. 2015). In the IPCC fifth assessment report (AR5), surface air temperature in Canada was projected to increase more than the global mean during this century, particularly in winter and in the north (IPCC 2013). Increases in future surface air temperature will lead to a change in precipitation type from snow to rain, which, in turn, will result in increases in rainfall occurrence frequency during the cold season over Canada (Harder et al. 2015; Jeong and Sushama 2018a). In addition, the IPCC AR5 suggested increases in future precipitation amounts over Canada, again with larger increases in winter and in northern Canada (IPCC 2013). These changes in wind speed coinciding with rainfall pattern in a future warmer climate could result in substantial implications for extreme DRWPs as well as existing buildings that were designed based on the design DRWP estimated from historical observations.

Studies based on historical meteorological station observations have been conducted to estimate design DRWP loads and risk assessments for building façades in different countries of the world, including Japan (Murakami et al. 1987), Australia (Choi 1992), Chile (PérezBella et al. 2013), Spain (Pérez-Bella et al. 2014), and Canada (Welsh et al. 1989; Cornick and Lacasse 2005). For Canada, Welsh et al. (1989) constructed a map and table for 5-year return level DRWP; these have been used in the design of residential and commercial buildings (NRCC 2015) as well as for selecting door and window systems (CSA 2018). However, few studies have quantified potential climate change impacts on the combined phenomenon of wind and rain and its impacts on buildings. Nik et al. (2015) assessed future moisture loads for building façades caused by wind-driven rain in Sweden using Swedish regional climate model (RCM) simulations, and found that higher amounts of moisture may accumulate in building walls. Nevertheless, studies focusing on projected changes to wind pressures coinciding with rainfall (i.e., DRWP) are not yet available for many countries, including Canada.

Realistic simulation of future climate variables at a fine spatial resolution with hourly temporal resolution are needed to quantitatively assess climate change impacts on compound wind-rain extremes like DRWP. At present, RCMs are the primary tools used to better resolve physical processes and add spatial detail to large-scale global climate model (GCM) projections. Output from Canadian RCMs have been used to project climate change impacts in Canada on both individual climate extremes, e.g., wind pressure and snow accumulation 
(Jeong and Sushama 2018b), precipitation (Diaconescu et al. 2016), and temperature (Whan et al. 2016; Jeong et al. 2016a, b), as well as compound events, e.g., rain-on-snow event (Jeong and Sushama 2018a) and atmospheric ice accretion (Jeong et al. 2018).

This study investigates projected changes to 5-year return level (RL) DRWPs used to design buildings and select door and window systems in Canada. Internal variability in the projected changes is quantified via a 15 member initial condition ensemble of simulations by the Canadian Centre for Climate Modeling and Analysis (CCCma) RCM (CanRCM4) driven by the Canadian Earth system model 2 (CanESM2) under historical and the Representative Concentration Pathway 8.5 (RCP8.5) radiative forcing scenarios. Projected changes to the 5year RL (design) DRWP are provided at specific levels of future global mean temperature change (GMTC) (e.g., $+1,+2$, and $+3{ }^{\circ} \mathrm{C}$ ) above the baseline 1986-2016 level. An analysis of projected changes in each of the relevant driving variables - surface (2-m) temperature, rainfall amount and frequency, and near-surface (10-m) wind speed - is used to gain insight into the relative influence of their changes on the design DRWP. In addition, future changes in risk, as quantified by marginal exceedance probabilities (rainfall $>1.8 \mathrm{~mm} / \mathrm{h}$ and wind pressure $>$ design DRWP) and joint exceedance probability, are estimated for the baseline period and at different levels of GMTC.

\section{Models and datasets}

\subsection{CanRCM4 simulations}

CanRCM4 was developed by CCCma of Environment and Climate Change Canada (ECCC). CanRCM4 uses the dynamical core from the Global Environmental Multiscale (GEM) model, which is ECCC's integrated numerical weather forecasting and data assimilation system (Côté et al. 1998), and shares the same physical parameterizations as the fourth-generation Canadian Atmospheric global climate model (CanAM4) (von Salzen et al. 2013), which also forms the atmospheric component of CanESM2 (Arora et al. 2011). In particular, CanRCM4 uses the deep-convection scheme of Zhang and McFarlane (1995) to parameterize the effects of cumulus clouds. The shallow-convection scheme of CanRCM4, which plays an important role in simulating the global water and energy cycles of the atmosphere, was developed by von Salzen et al. (2005). The Canadian Land Surface Scheme version 2.7 (Verseghy 2012) integrates the energy and water balances of the land surface. This scheme also produces surface parameters such as albedo and surface radiative and turbulent fluxes. Further details on the main components and physical parameterizations of CanRCM4 and its relationship with its parent global model CanESM2 are provided by Scinocca et al. (2016).

The experimental domain of CanRCM4 covers North America (NA) and adjoining oceans on a $0.44^{\circ}$ horizontal grid. Relevant variables are archived at an hourly time resolution. This study uses an ensemble of 15 initial condition simulations (Fyfe et al. 2017) driven by CanESM2 at the lateral boundaries under the historical (1950-2005) and RCP8.5 (20062100) scenarios. Ensemble members share the same forcings, differing only in initial conditions of the atmosphere and/or ocean state at the beginning of the historical simulation period; therefore, each member has different realization of internal variability under the given external forcing. As RCP8.5 is a high emission scenario with a radiative forcing of $8.5 \mathrm{~W} / \mathrm{m}^{2}$ by the end of the twenty-first century compared with the pre-industrial level (IPCC 2013), it is an appropriate scenario for business-as-usual and non-climate policy conditions. Furthermore, 
Sanford et al. (2014) reported that the RCP8.5 has closely matched recent historical emissions. Nevertheless, model uncertainty due to incomplete modeling of the physical processes and scenario uncertainty due to incomplete information of future emission scenario are not covered in this assessment. Hawkins and Sutton (2009) reported that the dominant sources of projection uncertainty at regional spatial scales are model uncertainty and internal variability for a decade or two, while they are model uncertainty and scenario uncertainty for time horizons of many decades or longer.

As different types of precipitation are not available as part of the CanRCM4 outputs, hourly rainfall amounts are calculated offline by the Bourgouin algorithm (Bourgouin 2000) from each CanRCM4 simulation using surface, 500, 850, and $1000 \mathrm{hPa}$ temperatures, surface air pressure, and precipitation for the 1986-2100 period. The Bourgouin (2000) algorithm is employed operationally in the numerical weather prediction models of Canada. When precipitation occurs, the Bourgouin algorithm calculates the rates of four precipitation types (i.e., snow, ice pellets, freezing precipitation, and rain) by first calculating areas of positive and negative energy from all possible pressure levels above the surface; the rate of each precipitation type is then determined based on the negative and/or positive areas and specified thresholds. Rain is diagnosed when precipitation falls through a warm enough near-surface layer for melting, even if passing through a cold layer $\left(<0{ }^{\circ} \mathrm{C}\right)$ aloft. Rain and snow are relatively easier to diagnose than the more rarely occurring ice pellet and freezing precipitation types.

\subsection{Observation dataset}

Hourly near-surface wind speed (10-m), precipitation types (e.g., "rain," "drizzle," "freezing rain," "freezing drizzle," "snow," "snow grains," "ice pellets," etc.) and their intensity (i.e., "light," "moderate," and "heavy"), as well as daily precipitation amounts are obtained from the ECCC climatological archives at 130 meteorological stations in Canada for the 1986-2016 period. The baseline period is representative of the most recent climate, which includes a warming signal in the global surface temperature of approximately $+0.2{ }^{\circ} \mathrm{C}$ (likely between 0.1 and $0.3^{\circ} \mathrm{C}$ ) per decade (IPCC 2018); thus, a decade difference of the baseline period (i.e., $0.2{ }^{\circ} \mathrm{C}$ difference of global surface temperature) can result in significant impacts on the results of this assessment. The changing rate of the target variable (i.e., design DRWP) with regard to the changes in global temperature will be shown in the result section. Meteorological stations selected are those with more than 10 complete years of observations during the analysis period; an observed year is considered to be complete when it contains fewer than $10 \%$ missing values. As hourly rainfall amounts are not always available from the observation stations, they are estimated by prorating the daily total precipitation amount for each precipitation type that occurs each hour, weighted by a nominal rate that is characteristic of each observed type and intensity (Welsh et al. 1989). For example, 1.8, 13.0, 0.6, and 2.5 weightings are allocated for "light rain," "heavy rain," "light snow," and "heavy snow," respectively, and the hourly rainfall rates are estimated from the daily total precipitation based on the given weightings. This weighting approach is an operational method of ECCC to estimate hourly rates of different types of precipitation. Although the weighting approach is expected to provide reliable estimates of hourly rainfall amounts (validated internally at few stations by ECCC), the performance of the approach has not yet been officially reported across Canada based on station observations due to lack of hourly observations. The table of the weightings of all precipitation types with their intensities and a detailed example to estimate hourly rainfall rates are available in Welsh et al. (1989). 


\section{Methodology}

Wind pressure $(Q ; \mathrm{Pa})$ is directly proportional to the air density $\left(\rho ; \mathrm{Pa} /(\mathrm{km} / \mathrm{h})^{2}\right)$ and the square of the wind speed $(V ; \mathrm{km} / \mathrm{h})$, i.e., $Q=0.5 \times \rho \times V^{2}$, where air density varies inversely with absolute temperature (changing $\sim 0.33 \%$ per ${ }^{\circ} \mathrm{C}$ ). Under the assumption of $0{ }^{\circ} \mathrm{C}$ air temperature with an atmospheric pressure of $101.325 \mathrm{kPa}$, hourly wind pressure is calculated using the following equation (Welsh et al. 1989):

$$
Q=0.04991 \times V^{2}
$$

Annual maximum series of hourly DRWPs are then constructed by extracting the annual maximum of hourly wind pressure, considering only hours when the rainfall rate exceeds the threshold rate of $1.8 \mathrm{~mm} / \mathrm{h}$. The threshold corresponds to light precipitation intensity (Welsh et al. 1989).

Estimation of the 5-year return level DRWP is carried out by fitting the Gumbel distribution to the series of annual maxima (Welsh et al. 1989; NRCC 2015). The Gumbel distribution is given by:

$$
F(x)=\exp \left(-\exp \left(-\frac{x-b}{a}\right)\right),
$$

where $F(x)$ represents the cumulative distribution function, $x$ is the value of the random variable $X$, and $a$ and $b$ are the scale and location parameters, respectively. The variable $X$ represents annual maxima of DRWP. The mean $\mu_{\mathrm{x}}$ and standard deviation $s_{x}$ of $X$ are equal to $b+0.5772 a$ and $a \pi / \sqrt{6}$, respectively. The return value $x_{T}$ for the $T$-year return period is given by:

$$
x_{T}=b-a \ln \left(-\ln \left(1-\frac{1}{\mathrm{~T}}\right)\right) .
$$

The two parameters are estimated by the method of moments following Welsh et al. (1989) and NRCC (2015).

Prior to the investigation of future projections, the ability of the CanRCM4 in simulating climatological statistics such as annual mean wind speed and total rainfall as well as the product of them, i.e., annual driving rain index, is evaluated by comparing these statistics calculated from CanRCM4 ensemble outputs with those observed for the 1986-2016 period. The driving rain index is a common indicator of driving rain water amount on a windward vertical surface (Welsh et al. 1989). Design DRWP and associated statistics such as annual total rainfall $(>1.8 \mathrm{~mm} / \mathrm{h})$ occurrence hours and annual maximum wind speed of the CanRCM4 ensemble are then compared with those of observations for the same period.

The pre-industrial (PI) 1850-1900 period might be a preferable reference period in climate change impact assessments; however, CanRCM4 simulations driven by CanESM2 are not available for the PI period. Alternatively, this study provides projected changes associated different future GMTC levels with respect to the baseline 1986-2016 period defined from surface temperature of CanESM2. Therefore, it should be notable that the surface temperature response of CanESM2 is known to be sensitive to radiative forcings; thus, it suggests higher increase compared to the other CMIP5 models (Schleussner et al. 2016). In particular, CanESM2 yields larger GMTC for the 1986-2005 period with respect to the PI period $\left(0.79^{\circ} \mathrm{C}\right)$, compared with global observations $\left(0.61{ }^{\circ} \mathrm{C}\right)$ (IPCC 2013). Therefore, in terms of 
CanESM2, the $+0.5,+1,+2$, and $+3{ }^{\circ} \mathrm{C}$ GMTC levels relative to the baseline are the same as $+1.5,+2,+3$, and $+4{ }^{\circ} \mathrm{C}$ levels relative to the PI period, as the GMTC from the PI to the baseline period is $+1{ }^{\circ} \mathrm{C}$ with an additional $+0.21{ }^{\circ} \mathrm{C}$ warming from the $1986-2005$ period. Statistical significance of the changes in terms of internal variability is assessed by applying two-sample t test at the $10 \%$ two-sided significance level between 15 members of baseline and future period values. The variables driving changes in design DRWP in CanRCM4 are investigated by comparing mean surface air temperature (2-m), total precipitation, autumnspring total rainfall, rainfall $(>1.8 \mathrm{~mm} / \mathrm{h})$ hours, and mean and maximum wind speeds between baseline and future $+2{ }^{\circ} \mathrm{C}$ GMTC periods. Finally, marginal risk ratios that future hourly rainfall $>$ the threshold $(1.8 \mathrm{~mm} / \mathrm{h})$ and future hourly wind pressure $>$ design DRWP estimated for the baseline period (hereafter referred to as "baseline design DRWP") as well as their joint risk ratios that future hourly DRWP $>$ the baseline design DRWP are evaluated for 31-year future periods at different levels of GMTC. The future risk ratio is the ratio of occurrence probability of the future period to the baseline for a given value of DRWP. Six Canadian regions are defined by considering both climatology and administrative district (Fig. 1a), and are used to evaluate climate change impacts on the design DRWP and associated driving climate variables at the sub-country level.

\section{Results}

\subsection{Evaluation}

As conventional design DRWPs have been estimated based on station measurements, it is important to verify performance of the CanRCM4 simulations against station observations. However, the validity of these comparisons is debatable as RCM variables represent spatial averages over a grid box rather than the local values at a point. Moreover, internal variability of station observations reflects a single realization of the climate system; therefore, differences between RCM simulations and observations might not represent true errors (Jeong et al. 2019). Nevertheless, the CanRCM4 ensemble reproduces well the spatial distribution of observed annual total rainfall amounts; large magnitudes are simulated over British Columbia and the Atlantic region, and small values over the North and Prairies regions. An R-squared value of 0.9 is found between station observations and CanRCM4 ensemble averages (EA) at the nearest neighboring grid points for the 1986-2016 period (Fig. $1 \mathrm{~b}$ and c). Therefore, annual total magnitudes of hourly rainfall in CanRCM4, as diagnosed by the Bourgouin approach, are in good agreement with station observations. CanRCM4, however, tends to overestimate annual total rainfall amounts across Canada. This is originally caused by overestimation of precipitation amounts in this RCM (not shown), as reported by Whan and Zwiers (2016). Although annual mean wind speed exhibits weaker spatial variability in comparison to rainfall, the CanRCM4 ensemble explains 52\% of the spatial variability of observed annual mean wind speed (spatial correlation coefficient of 0.72 for the validation period). This result is comparable with the findings of Jeong and Sushama (2018b), who showed that the ERA-Interim reanalysis, an observationally constrained historical dataset, and Canadian Regional Climate Model version 5 (CRCM5) explain 53\% and 58\% of the spatial variability of observed station annual mean wind speeds, respectively, over Canada for 1981-2010 period. Both CanRCM4 EA and observations display large values over western and eastern coastal areas, eastern North, southern Prairies, northern Quebec and Atlantic, and southern Ontario (i.e., Great Lake 
(a)

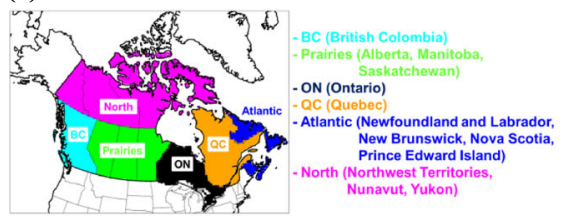

(b)

Obs.

CanRCM4 EA

(c)
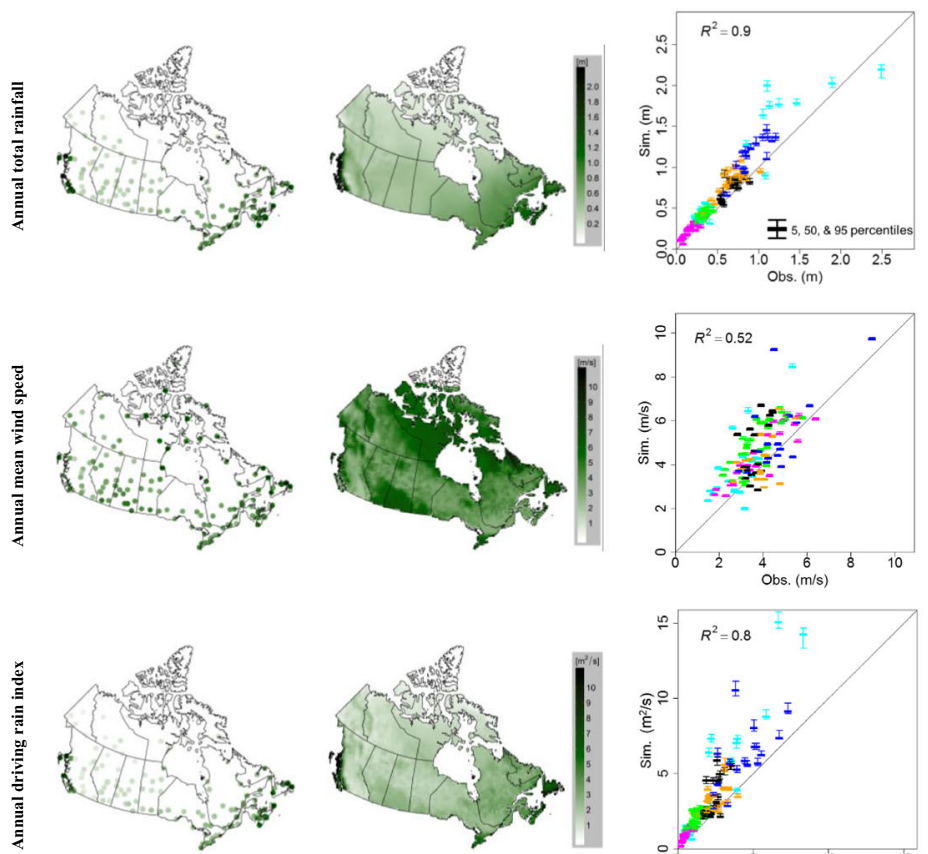

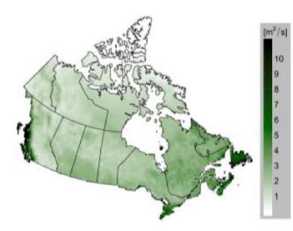

(d)
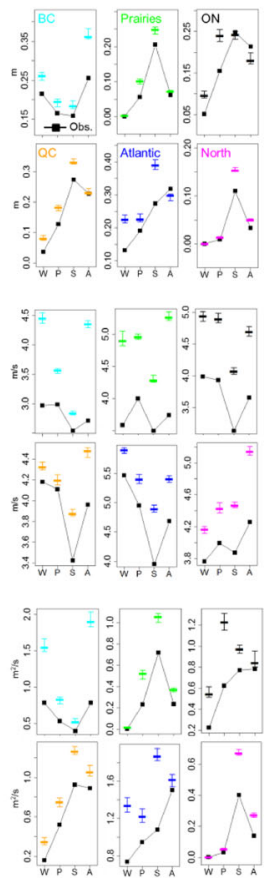

Fig. 1 (a) Six Canadian assessment regions of this study. (b) Spatial, (b) scatter, and (c) seasonal plots of 130 weather station observations and CanRCM4 ensemble simulation for annual total rainfall, annual mean wind speed, and annual driving rain index for 1986-2016 period. Colors of symbols in (c) and (d) represent the six regions defined in (a), and "W," "P," "S," and "A" in (d) represent winter (DJF), spring (MAM), summer (JJA), and autumn $(\mathrm{SON})$, respectively

area). Again, there is some overestimation in annual mean wind speed of CanRCM4 EA when compared with station observations. Consequently, CanRCM4 reproduces well the spatial distribution of observed annual driving rain index by exhibiting large magnitudes at the western and eastern coastal regions and southern Ontario for the validation period, although it overestimates this index due to overestimation of rainfall amount and mean wind speed. The high exposure of driving rain over the western and eastern coastal regions is in good agreement with findings by Welsh et al. (1989) obtained from an hourly rainfall and wind speed dataset measured at 141 Canadian weather stations. CanRCM4 simulates seasonal variability of the three statistics properly (Fig. 1d), indicating that it reproduces the intra-annual variability of observed rainfall amount and mean wind speed as well as the associated driving rain index.

As shown in Fig. 2, the CanRCM4 ensemble tends to overestimate observed annual rainfall ( $>1.8 \mathrm{~mm} / \mathrm{h}$; the threshold of the DRWP) occurrence hours over wet regions (i.e., British Columbia and Atlantic) but performs well over the other regions (R-squared value of 0.73 ). The 
overestimation of rainfall occurrence hours over the wet regions is mainly caused by the wet bias in rainfall amounts (shown in Fig. 1). CanRCM4 yields similar performance for annual maximum wind speed and annual mean wind speed in the validation period; similar spatial patterns and similar R-squared values are obtained between observations and CanRCM4 EA for these two variables. However, CanRCM4 generally overestimates annual mean wind speed but underestimates annual maximum wind speed. Finally, The CanRCM4 ensemble shows better performance for design DRWP than either annual mean or maximum wind speed, reproducing $57 \%$ of the spatial variability of observed design DRWP (spatial correlation coefficient of 0.75 ). The spatial pattern of the design DRWP is more similar to that of annual maximum wind speed than rainfall occurrence frequency, indicating that extreme wind speed is the main determinant of the DRWP. In contrast, the spatial pattern of the annual driving rain index is more similar to that of annual total rainfall amount than annual mean wind speed (Fig. 1b).

\subsection{Projected changes}

The CanRCM4 ensemble projects statistically significant increases, with respect to simulated historical variability, in future design DRWP over western, eastern and

(a)
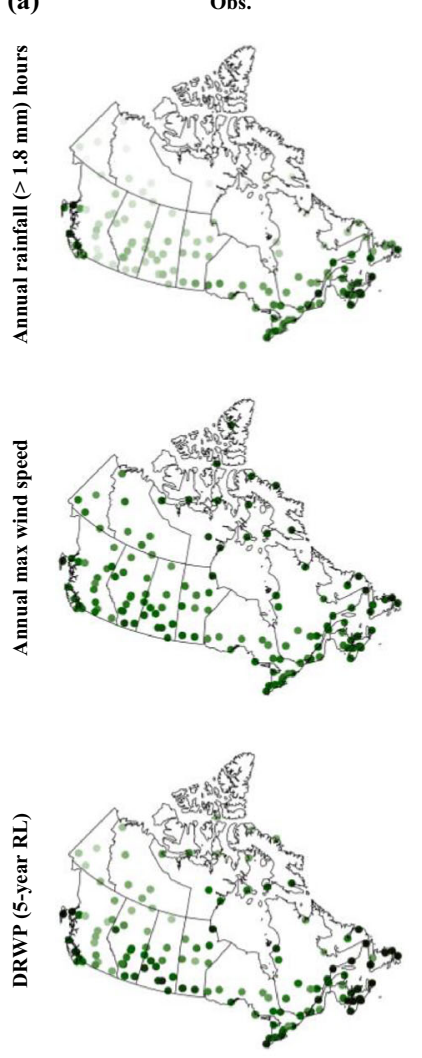

CanRCM4 EA
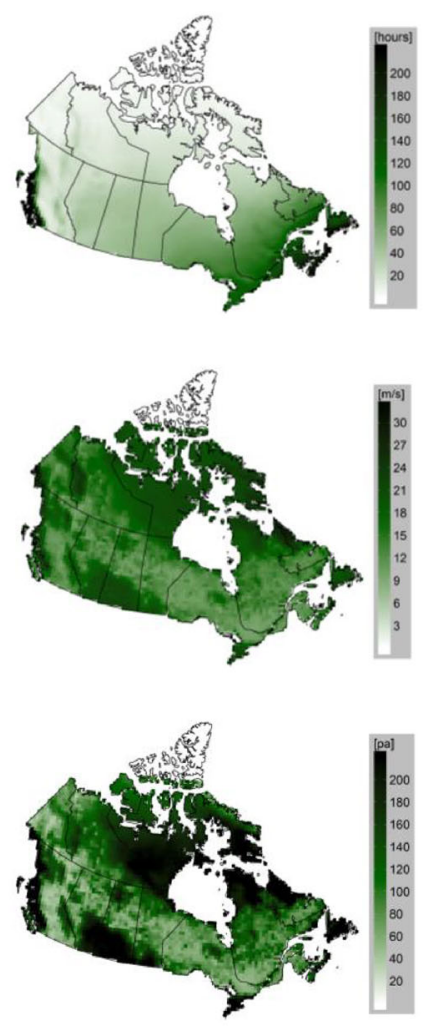

(b)
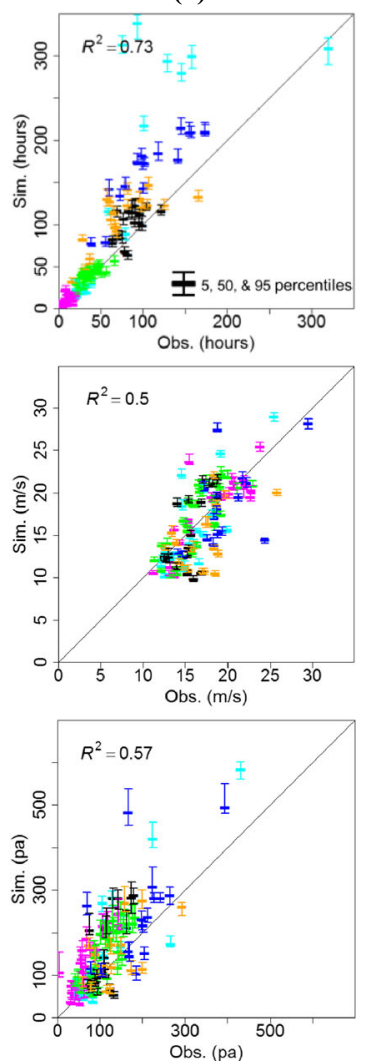

Fig. 2 (a) Spatial and (b) scatter plots of weather station observations and CanRCM4 ensemble simulation for annual rainfall (>1.8 mm) hours, annual maximum wind speed, and 5-year return level (RL) DRWP for 19862016 period. Colors of symbols in (b) represent the six Canadian regions defined in Fig. 1a 
northern Canada. The spatial extent and relative magnitude of the significant increases tends to increase with GMTC (Fig. 3a). The CanRCM4 ensemble, however, projects statistically insignificant changes in future design DRWP over central and northern Prairies, northwestern Ontario, and southern North regions. Regional averages of the projected changes for the six Canadian regions show overall increases in the relative magnitude of the design DRWP as GMTC levels increase (Fig. 3b). On average, the CanRCM4 ensemble projects increases in the design DRWP at $+3.5{ }^{\circ} \mathrm{C}$ GMTC level (i.e., 2062-2092 period) of about 30\% (39 Pa) for British Columbia, 26\% (31 Pa) for North, 17\% (25 Pa) for Quebec, 16\% (24 Pa) for Atlantic, 10\% (10 Pa) for Ontario, and $6 \%(8 \mathrm{~Pa})$ for Prairies. In addition, the 5-95 percentiles ranges of the design DRWP for British Columbia, Quebec, and North regions exclude zero change when GMTCs equal or exceed the $+0.5^{\circ} \mathrm{C}$ level (i.e., 2000-2030 period), indicating statistically significant changes with regard to the internal variability at the $10 \%$ significance level. Therefore, increase in DRWP could be an emerging risk for existing buildings over these regions that were designed based on the design DRWP estimated from historical observations. The 5-95 percentiles ranges of the regional averages for Atlantic, Prairies, and Ontario regions exclude zero change at higher levels of global temperature increases (i.e., +2.5 and $+3.5{ }^{\circ} \mathrm{C}$ GMTC levels).
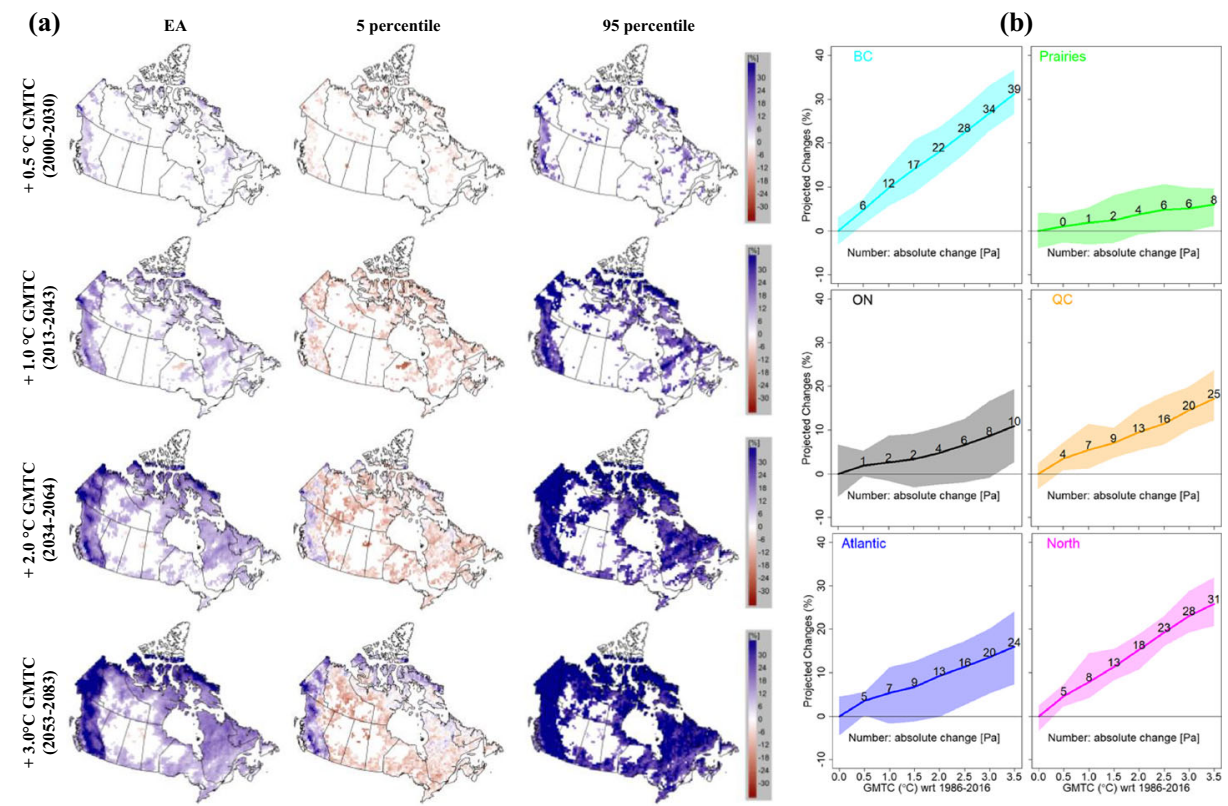

Fig. 3 (a) Projected changes of CanRCM4 (ensemble average (EA) and 5th \& 95th percentiles) to design DRWP for $+0.5,+1,+2$, and $+3{ }^{\circ} \mathrm{C}$ global mean temperature change (GMTC) levels, which are 2000-2030, 20132043, 2034-2064, and 2053-2083 periods based on CanESM2 RCP8.5 scenario, respectively, with respect to the baseline 1986-2016 period. Projected changes are marked by colors when baseline and future ensembles are statistically significant with two-sample t-test at the $10 \%$ significance level. (b) Regional average of the projected changes for the six Canadian regions (Fig. 1a) as a function of GMTC. Minimum and maximum values of areas and lines represent 5, 95, and 50th percentiles, respectively, obtained from the ensemble. Numbers represent mean absolute changes of design DRWP [Pa] for the GMTC levels 
According to the definition of DRWP (i.e., Eq. 1), changes in the design DRWP are primarily driven by changes in hourly wind speeds, considering only those hours with greater than $1.8 \mathrm{~mm}$ rainfall. Increases in the rainfall occurrence frequency could be caused by changes in precipitation types from solid to liquid due to increases in air temperature and/or increases in precipitation amounts due to warming-induced increases in atmospheric water vapor. The CanRCM4 ensemble projects increases in future rainfall $(>1.8 \mathrm{~mm} / \mathrm{h})$ occurrence frequency across Canada, along with increases in future surface air temperature, precipitation amounts, and cold season (autumn-spring) rainfall amounts (Fig. 4). The increase in future rainfall occurrence frequency obtained from the ensemble is also in a good agreement with the results from Jeong and Sushama (2018a) over Canada. The spatial pattern of projected changes to rainfall occurrence frequency is similar to the spatial pattern of changes in design DRWP shown in Fig. 3 for the $+2{ }^{\circ} \mathrm{C}$ GMTC level (i.e., 2034-2064 period); both variables display larger increases over British Columbia, North, and northern parts of Quebec and Atlantic regions. The projected changes to rainfall frequency can explain $67 \%$ of the spatial distribution of the projected changes to design DRWP over Canada at the $+2{ }^{\circ} \mathrm{C}$ GMTC level with a spatial correlation coefficient of 0.82 between the two projections. This indicates that the increase in the rainfall occurrence frequency is a main contributor to the increase in design DRWP, particularly over those regions. The CanRCM4 ensemble, however, projects small changes to annual mean wind speed, mostly smaller than $3 \%$ for the $+2{ }^{\circ} \mathrm{C}$ GMTC level, with some increases over western coastal region of British Columbia, northern parts of Ontario and Quebec, and North regions, but decreases for most parts of British Columbia and Prairies and southern parts of Ontario, Quebec, and Atlantic regions. CanRCM4 ensemble also projects small changes to annual maximum wind speed with some increases for British Columbia, western North, and northern Quebec and Atlantic regions, which are slightly different from the spatial pattern of mean wind speed. These relatively modest changes in mean and extreme wind speeds of CanRCM4 are generally consistent with the findings from Gastineau and Soden (2009), Kumar et al. (2015), and Jeong and Sushama (2018b) over Canada. Nevertheless, the projected changes to annual maximum wind speed can explain only $13 \%$ of the spatial distribution of the projected changes to design DRWP over Canada at the $+2{ }^{\circ} \mathrm{C}$ GMTC level.

(a) Annual mean air temperature (2-m)

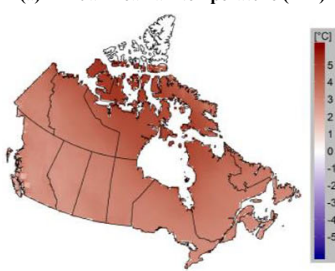

(d) Annual rainfall ( $>1.8 \mathrm{~mm})$ hours

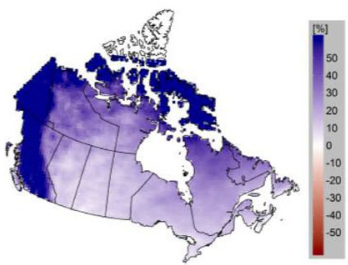

(b) Annual total precipitation

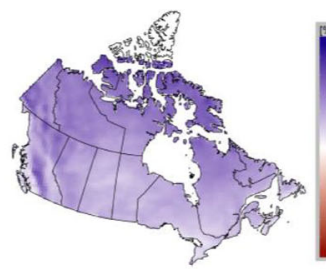

(e) Annual mean wind speed

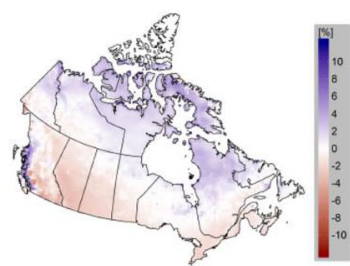

(c) Autumn-spring total rainfall

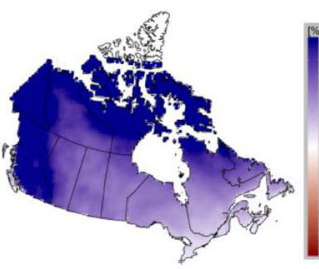

(f) Annual max wind speed

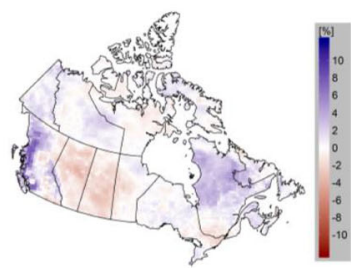

Fig. 4 Projected changes to (a) annual mean air temperature (2-m), (b) annual total precipitation, (c) autumnspring total rainfall, annual rainfall $(>1.8 \mathrm{~mm}$ ) hours, (e) annual mean wind speed, and (f) annual max wind speed from CanRCM4 (ensemble average) at $+2{ }^{\circ} \mathrm{C}$ GMTC level with respect to the baseline period 
The compound influence of rain/wind on the design DRWP is further investigated in the context of risk assessment by comparing future risk ratios of marginal occurrence probabilities for hourly rainfall larger than $1.8 \mathrm{~mm}$, hourly wind pressure higher than the baseline design DRWP, and their joint occurrence probability (Fig. 5a). The CanRCM4 ensemble projects increases in future risk ratios of the hourly rainfall $(>1.8 \mathrm{~mm})$ occurrence across Canada with higher increases for British Columbia, western and northern parts of North regions, and the future risk ratios show larger increases at higher levels of GMTC in these regions. In particular, the rainfall occurrence probability for $+3{ }^{\circ} \mathrm{C}$ GMTC level is more than two times higher than in the baseline period for these regions. Again, CanRCM4 ensemble projects much smaller changes in future risk ratios of hourly wind pressures compared to those of hourly rainfall occurrence. It suggests decreases in future occurrence probability for central and northern parts of Prairies and some southern parts of Ontario, Quebec and Atlantic regions but increases for the western coastal regions of British Columbia, and central and northern parts of Quebec and Atlantic regions. This spatial pattern of future risk ratios is quite consistent with that of annual maximum wind speeds, shown in Fig. 4f. Consequently, the spatial pattern of the future risk ratios of the DRWP is generally consistent with that of rainfall occurrence probability. Nevertheless, the future risk ratio of the DRWP displays a decrease for central and northern Prairies and some larger increases than that of rainfall occurrence for British Columbia and northern parts of Quebec and Atlantic regions, due to the influences of the changes in hourly wind pressure. These relationships between future marginal and joint occurrence risks are consistent in the regional averages for the six Canadian regions (Fig. 5b). In particular, regional
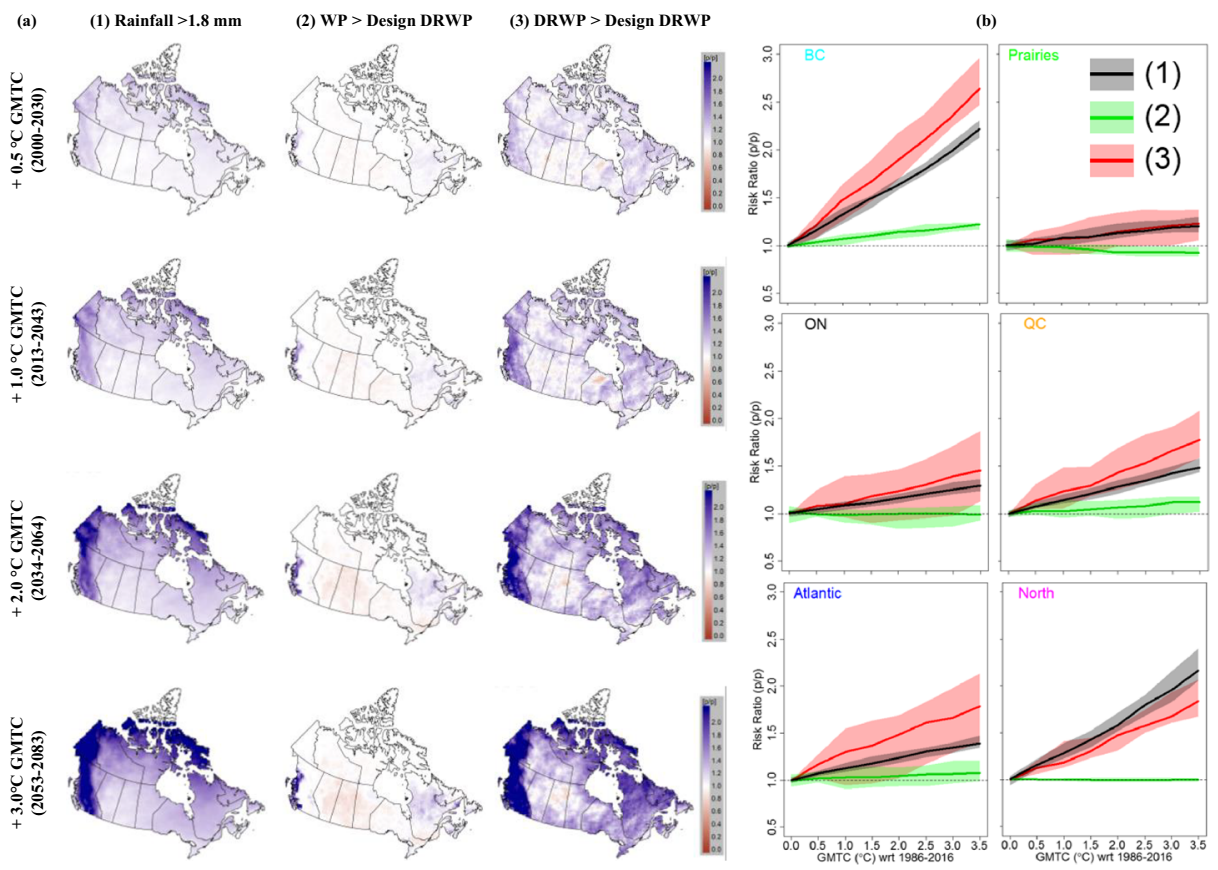

Fig. 5 (a) Risk ratios of (1) rainfall $>1.8 \mathrm{~mm}$ and (2) wind pressure (WP) and (3) DRWP> design DRWP (estimated for the baseline period) from CanRCM4 (ensemble average) for $+0.5,+1,+2$, and $+3{ }^{\circ} \mathrm{C}$ global mean temperature change (GMTC) levels with respect to the baseline period. (b) Regional average of the risk ratios for the six Canadian regions as a function of GMTC, where minimum and maximum values of areas and lines represent 5, 95, and 50th percentiles, respectively, obtained from the ensemble 
averages of the future risk ratios of the design DRWP show overall increases for the six regions as GMTC levels increase, mainly due to the increases in future risk ratios of the hourly rainfall occurrences. Increases in the wind pressures additionally contribute to those in design DRWP for British Columbia, Quebec, and Atlantic regions. The risk ratio of the design DRWP exhibits larger 5-95 percentiles ranges than the two marginal events; internal variability in the compound event is larger than its marginal components.

\section{Summary and discussion}

This study investigates projected changes to extreme driving rain wind pressure (DRWP) used in the design of buildings and their window systems over Canada for future periods with different levels of global mean temperature change (GMTC) (relative to baseline 1986-2016 period) using a 15 member initial condition ensemble of CanRCM4 driven by CanESM2 under the RCP8.5 scenario. The compound influence of rain and wind on DRWP (i.e., hourly wind pressure coinciding with rainfall exceeding $1.8 \mathrm{~mm} / \mathrm{h}$ ) and the range in the design (5-year RL) DRWP due to internal variability are investigated using the hourly CanRCM4 ensemble.

The CanRCM4 ensemble explains $52 \%$ of the spatial variability of observed climatological mean wind speeds from 130 stations for the 1986-2016 period, which is similar to the previously reported performance by Jeong and Sushama (2018b) over Canada based on the ERA-Interim reanalysis and CRCM5 simulations. It also explains $90 \%$ of the spatial variability of observed climatological rainfall amounts and $80 \%$ of observed driving rain indices, the products of climatological mean wind speeds and rainfall amounts, for the validation period. Moreover, the CanRCM4 ensemble shows an ability to explain the spatial variability of design DRWP (57\%) and relevant driving variables, i.e., annual maximum wind speed (50\%) and rainfall $(>1.8 \mathrm{~mm} / \mathrm{h}$ ) occurrence frequency $(73 \%)$, across Canada for the same period. Both driving rain index and design DRWP are compound events driven by wind that coincides with rainfall; however, their spatial distributions are primarily decided by total rainfall amount and extreme wind speed, respectively.

Future projections from the CanRCM4 ensemble suggests statistically significant increases in future design DRWP over western, eastern, and northern Canada; the areal extent and relative magnitude of the increases are larger for the higher GMTC levels. However, insignificant changes are projected for some parts of central and northern Prairies, northwestern Ontario, and southern North regions. The largest increase for British Columbia (30\%, $39 \mathrm{~Pa})$, the second largest increases for North (26\%, $31 \mathrm{~Pa})$, Quebec (16\%, $25 \mathrm{~Pa})$ and Atlantic (16\%, $24 \mathrm{~Pa})$, and the least increases for Ontario $(10 \%, 10 \mathrm{~Pa})$ and Prairies $(6 \%, 8 \mathrm{~Pa})$ are expected on average in the design DRWP at $+3.5^{\circ} \mathrm{C}$ GMTC level with respect to the baseline. A change in future rainfall $(>1.8 \mathrm{~mm} / \mathrm{h})$ occurrence frequency is identified as a main factor leading to changes in future design DRWP, even though the spatial pattern of the baseline design DRWP is mostly determined by wind speeds. The changes in future rainfall occurrence frequency is caused by changes in future surface air temperature and precipitation amounts, with large increases for British Columbia, North, and northern parts of Quebec and Atlantic regions of Canada. Risk ratio assessment also reveals that future risk of DRWP exceeding the baseline design DRWP is highly dependent on future rainfall frequency exceeding the threshold $1.8 \mathrm{~mm} / \mathrm{h}$. However, increases in future extreme wind speeds can additionally contribute the increases in future risk ratios of the design DRWP for British Columbia and northern parts of Quebec and Atlantic regions. 
There is some confidence in projected changes to the design DRWP from the CanRCM4 ensemble, as these changes are primarily driven by increases in future rainfall occurrence frequency caused by increases in air temperature and precipitation amounts, which are relatively well understood over Canada as compared to changes in mean and extreme wind speeds. Although this study employs a single RCM with one driving GCM under the RCP8.5, an attempt is made to separate projection uncertainty due to internal variability from uncertainty due to differences in climate model sensitivity and in emission scenarios by expressing projected changes as a function of different future GMTC levels. Nevertheless, the projected changes could be most appropriate for business-as-usual and non-climate policy emission scenario. Projected changes to design DRWP quantified in this study could help inform development of climate-resilient design standards, codes, and guides for buildings for future warming climate. Increases in design DRWP are found as an emerging risk factor for existing building over British Columbia, Quebec, and North regions, and a consideration for managing and designing buildings across Canada. As there is still unknown and unquantified uncertainty in the projected changes due to the difficulty in simulating small-scale convective wind storms and extratropical cyclones with CanRCM4 (Seiler et al. 2018), further investigation with improved modeling systems will be necessary.

Acknowledgments We thank the Canadian Centre for Climate Modeling and Analysis (CCCma) for providing the CanRCM4 simulations used in this study. CanRCM4 outputs are available for download from https://data.ec. gc.ca/data/climate/scientificknowledge/the-canadian-regional-climate-model-large-ensemble/. We also would like to thank the anonymous reviewers for their constructive comments.

Open Access This article is licensed under a Creative Commons Attribution 4.0 International License, which permits use, sharing, adaptation, distribution and reproduction in any medium or format, as long as you give appropriate credit to the original author(s) and the source, provide a link to the Creative Commons licence, and indicate if changes were made. The images or other third party material in this article are included in the article's Creative Commons licence, unless indicated otherwise in a credit line to the material. If material is not included in the article's Creative Commons licence and your intended use is not permitted by statutory regulation or exceeds the permitted use, you will need to obtain permission directly from the copyright holder. To view a copy of this licence, visit http://creativecommons.org/licenses/by/4.0/.

\section{References}

Arora VK, Scinocca JF, Boer GJ, Christian JR, Denman KL, Flato GM, Kharin VV, Lee WG, Merryfield WJ (2011) Carbon emission limits required to satisfy future representative concentration pathways of greenhouse gases. Geophys Res Lett 38:L05805. https://doi.org/10.1029/2010GL046270

Blocken B, Carmeliet J (2004) A review of wind-driven rain research in building science. J Wind Eng Ind Aerodyn 92(13):1079-1130

Blocken B, Carmeliet J, Poesen J (2005) Numerical simulation of the wind-driven rainfall distribution over small-scale topography in space and time. J Hydrol 315(1-4):252-273

Bourgouin P (2000) A method to determine precipitation types. Weather Forecast 15(5):583-592

Canadian Standard Association (CSA) (2018) CAN/CSA-A440.4-18 Window, door, and skylight installation, CSA, Mississauga, Ontario

Choi ECC (1992) Extreme wind speeds during rainfall. In Australian Wind Engineering Society 2nd Workshop, Melbourne, Australia

Cornick SM, Lacasse MA (2005) A review of climate loads relevant to assessing the watertightness performance of walls, windows, and wall-window interfaces. J ASTM Int 2(10):1-15

Côté J, Gravel S, Méthot A, Patoine A, Roch M, Staniforth A (1998) The operational CMC-MRB global environmental multiscale (GEM) model. Part I: design considerations and formulation. Mon Weather Rev 126(6):1373-1395 
Diaconescu EP, Gachon P, Laprise R, Scinocca JF (2016) Evaluation of precipitation indices over North America from various configurations of regional climate models. Atmosphere-Ocean 54(4):418-439

Foulds SA, Warburton J (2007) Significance of wind-driven rain (wind-splash) in the erosion of blanket peat. Geomorphology 83(1-2):183-192

Fyfe JC, Derksen C, Mudryk L, Flato GM, Santer BD, Swart NC, Molotch NP, Zhang X, Wan H, Arora VK, Sciocca J, Jiao Y (2017) Large near-term projected snowpack loss over the western United States. Nat Commun 8:14996. https://doi.org/10.1038/ncomms14996

Gastineau G, Soden BJ (2009) Model projected changes of extreme wind events in response to global warming. Geophys Res Lett 36(10):L10810. https://doi.org/10.1029/2009GL037500

Harder P, Pomeroy JW, Westbrook CJ (2015) Hydrological resilience of a Canadian Rockies headwaters basin subject to changing climate, extreme weather, and forest management. Hydrol Process 29(18):3905-3924

Hawkins E, Sutton R (2009) The potential to narrow uncertainty in regional climate predictions. Bull Am Meteorol Soc 90(8):1095-1108

Hovind EL (1965) Precipitation distribution around a windy mountain peak. J Geophys Res 70(14): $3271-3278$

IPCC (2012) Managing the risks of extreme events and disasters to advance climate change adaptation. A special report of working groups I and II of the intergovernmental panel on climate change [field CB, Barros V, stocker TF, Qin D, Dokken DJ, Ebi KL, Mastrandrea MD, Mach KJ, Plattner G-K, Allen SK, Tignor M, Midgley PM (eds.)]. Cambridge University press, Cambridge, UK, and New York, NY, USA

IPCC (2013) Climate change 2013. The physical science basis. Contribution of working group I to the fifth assessment report of the intergovernmental panel on climate change [stocker TF, Qin D, Plattner G-K, Tignor M, Allen SK, Boschung J, Nauels a, Xia Y, Bex V, and Midgley PM (eds.)], Cambridge University press, Cambridge, United Kingdom and New York, NY, USA

IPCC (2018) Global Warming of $1.5^{\circ} \mathrm{C}$. An IPCC Special Report on the impacts of global warming of $1.5^{\circ} \mathrm{C}$ above pre-industrial levels and related global greenhouse gas emission pathways, in the context of strengthening the global response to the threat of climate change, sustainable development, and efforts to eradicate poverty [Masson-Delmotte V, Zhai P, Pörtner H-O, Roberts D, Skea J, Shukla PR, Pirani A, MoufoumaOkia W, Péan C, Pidcock R, Connors S, Matthews JBR, Chen Y, Zhou X, Gomis MI, Lonnoy E, Maycock T, Tignor M, Waterfield T. (eds.)]. In Press

Jeong DI, Sushama L (2018a) Rain-on-snow events over North America based on two Canadian regional climate models. Clim Dyn 50(1-2):303-316

Jeong DI, Sushama L (2018b) Projected changes to extreme wind and snow environmental loads for buildings and infrastructure across Canada. Sustain Cities Soc 36:225-236

Jeong DI, Sushama L, Diro GT, Khaliq MN (2016a) Projected changes to winter temperature characteristics over Canada based on an RCM ensemble. Clim Dyn 47(5):1351-1366

Jeong DI, Sushama L, Diro GT, Khaliq MN, Beltrami H, Caya D (2016b) Projected changes to high temperature events for Canada based on a regional climate model ensemble. Clim Dyn 46(9-10):3163-3180

Jeong DI, Sushama L, Vieira MJF, Koenig KA (2018) Projected changes to extreme ice loads for overhead transmission lines across Canada. Sustain Cities Soc 39:639-649

Jeong DI, Cannon AJ, Zhang X (2019) Projected changes to extreme freezing precipitation and design ice loads over North America based on a large ensemble of Canadian regional climate model simulations. Nat Hazards Earth Syst Sci 19:857-872

Johansson B, Chen D (2003) The influence of wind and topography on precipitation distribution in Sweden: statistical analysis and modelling. Int J Climatol 23(12):1523-1535

Kikuchi N, Matsuzaki Y, Yukino T, Ishida H (2003) Aerodynamic drag of new-design electric power wire in a heavy rainfall and wind. J Wind Eng Ind Aerodyn 91(1-2):41-51

Kumar D, Mishra V, Ganguly AR (2015) Evaluating wind extremes in CMIP5 climate models. Clim Dyn 45(12):441-453

McInnes KL, Erwin TA, Bathols JM (2011) Global climate model projected changes in $10 \mathrm{~m}$ wind speed and direction due to anthropogenic climate change. Atmos Sci Lett 12(4):325-333

Mirrahimi S, Lim CH, Surat M (2015) Review of method to estimation of wind-driven rain on building facade. Adv Environ Biol 9(2):18-23

Murakami S, Iwasa Y, Morikawa Y, Chino N (1987) Extreme wind speeds for various return periods during rainfall. J Wind Eng Ind Aerodyn 26(1):105-125

Nik VM, Mundt-Petersen SO, Kalagasidis AS, De Wilde P (2015) Future moisture loads for building facades in Sweden: climate change and wind-driven rain. Build Environ 93:362-375

NRCC (2015) National Building Code of Canada. Institute for Research in construction, National Research Council of Canada, Ottawa, Ontario

Pérez-Bella JM, Domínguez-Hernández J, Cano-Suñén E, del Coz-Díaz JJ, Alonso-Martínez M (2013) Global analysis of building façade exposure to water penetration in Chile. Build Environ 70:284-297 
Pérez-Bella JM, Domínguez-Hernández J, Cano-Suñén E, del Coz-Díaz JJ, Martín-Rodríguez Á (2014) Procedure for a detailed territorial assessment of wind-driven rain and driving-rain wind pressure and its implementation to three Spanish regions. J Wind Eng Ind Aerodyn 128:76-89

Sanford T, Frumhoff PC, Luers A, Gulledge J (2014) The climate policy narrative for a dangerously warming world. Nat Clim Chang 4(3):164. https://doi.org/10.1038/nclimate2148

Schleussner CF et al (2016) Differential climate impacts for policy-relevant limits to global warming: the case of $1.5^{\circ} \mathrm{C}$ and $2^{\circ} \mathrm{C}$. Earth Syst Dynam 7:327-351

Scinocca JF et al (2016) Coordinated global and regional climate modelling. J Clim 29(1):17-35

Seiler C, Zwiers FW, Hodges KI, Scinocca JF (2018) How does dynamical downscaling affect model biases and future projections of explosive extratropical cyclones along North America's Atlantic coast? Clim Dyn 50(1-2):677-692

Van Stan JT, Siegert CM, Levia DF Jr, Scheick CE (2011) Effects of wind-driven rainfall on stemflow generation between codominant tree species with differing crown characteristics. Agric For Meteorol 151(9):12771286

Verseghy D (2012) CLASS-the Canadian land surface scheme (version 3.6). Tech. Rep., Climate Research Division, Science and Technology Branch, Environment Canada

von Salzen K, McFarlane NA, Lazare M (2005) The role of shallow convection in the water and energy cycles of the atmosphere. Clim Dyn 25:671-688

von Salzen K, Scinocca JF, McFarlane NA, Li J, Cole JNS, Plummer D, Verseghy D, Reader MC, Ma X, Lazare M, Solheim L (2013) The Canadian fourth generation atmospheric global climate model (CanAM4), part I: representation of physical processes. Atmosphere-Ocean 51(1):104-125

Welsh LE, Skinner WR, Morris RJ (1989) A Climatology of Driving Rain Wind Pressures for Canada. Climate and Atmospheric Research Directorate Draft Report, Environment Canada, Atmospheric Environment Service, Canada

Whan K, Zwiers F (2016) Evaluation of extreme rainfall and temperature over North America in CanRCM4 and CRCM5. Clim Dyn 46(11-12):3821-3843

Whan K, Zwiers F, Sillmann J (2016) The influence of atmospheric blocking on extreme winter minimum temperatures in North America. J Clim 29(12):4361-4381

Zhang GJ, McFarlane NA (1995) Sensitivity of climate simulations to the parameterization of cumulus convection in the CCC-GCM. Atmosphere-Ocean 3:407-446

Publisher's note Springer Nature remains neutral with regard to jurisdictional claims in published maps and institutional affiliations.

\section{Affiliations}

\section{Dae II Jeong ${ }^{1} \cdot$ Alex J. Cannon ${ }^{2} \cdot$ Robert J. Morris ${ }^{3}$}

1 Climate Research Division, Environment and Climate Change Canada, 4905 Dufferin Street, Toronto, Ontario M3H 5T4, Canada

2 Climate Research Division, Environment and Climate Change Canada, Victoria, British Columbia V8W 2Y2, Canada

3 Meteorological Service of Canada, Environment and Climate Change Canada, Toronto, Ontario M3H 5T4, Canada 